\title{
Assessment of Implementing Cloud-based Career and Educational Guidance System using Fuzzy Logic Modelling
}

\author{
Hosam F. El-Sofany
}

\begin{abstract}
The career guidance process for graduates and students is affected by many factors; this, in turn, has motivated researchers to use a variety of scientific methodologies and techniques for proposing career guidance systems and solving related problems. The choice of right career not only positively affects the professional life of graduates, but also the academic life of students. As a result, the significance of developing career and educational guidance systems has increased. In this paper, the researcher discusses the effectiveness of using the proposed cloud-based career and educational guidance system to help students and graduates move to the professional world. The main objectives of the system include helping students choose their majors; helping graduates choose a career that is appropriate to their educational skills, practical experiences, and scientific ability; providing graduates and students with training courses required for specific careers. The proposed system is presented as a "Career-as-a-Service" cloud model. In this paper, the use of Fuzzy Logic for defining system inputs, processes, and outputs as a new representation for career and educational guidance system parameters is introduced. Cronbach's alpha tests are used for measuring the validity and reliability of the study questionnaires' content. In this study, several analysis methods such as Spearman correlation, stepwise multiple linear regression, skewness, mean, and standard deviation have been used to determine the effect and performance of the proposed system through dominating factors such as gender, age, class standing, enrolment status, specialization, and city.

Keywords: Career guidance, Educational guidance, Cloud computing, Fuzzy Logic.
\end{abstract}

\section{INTRODUCTION}

$\mathrm{O}_{\text {ne of the important objectives of the students is how to }}$ choose the right major and career because their decision will positively support their academic level and professional life. As a result, the researchers get attracted to scientific researches in career and educational guidance services that include several factors and criteria such as career information, career advising, and professional instruction. In this paper, the researcher has used some important terminologies and concepts including:

Revised Manuscript Received on February 05, 2020.

* Correspondence Author

Hosam F. El-Sofany*, King Khalid University, Kingdom of Saudi Arabia, Abha. Email: helsofany@kku.edu.sa

Cairo Higher Institute for Engineering, Computer Science and Management, Cairo, Egypt.

(C) The Authors. Published by Blue Eyes Intelligence Engineering and Sciences Publication (BEIESP). This is an open access article under the CC BY-NC-ND license (http://creativecommons.org/licenses/by-nc-nd/4.0/)
Career-- the daily life of individuals that incorporates work, learning and relaxation activities, and other aspects of life $[1,2]$.

Career Development Process-- the life-long technique of administrating learning, work, activities, and changes to upgrade life and create future [1]. Career development enables students to pay attention to select their careers or areas of study to proceed toward their future goals. Educational or non-educational institutions should offer guidance in the form of definitive approaches to develop career growth and support their students and employees to manage their careers successfully.

Career Education: refers to the improvement of capabilities, and performance of students through a planned program of learning which assists students to make the right decisions regarding their studies, along with work choices and ensure their actual involvement in professional life [3, 4]

Cloud Computing-- the fifth generation of networks and a successful model of service-oriented computing that developed how computing infrastructure is used and managed. Also, it can hold assets, providing services to consumers and helpful, on-demand access to an incorporated, shared pool of enrolling assets to convey by a nominal administration overhead and with excessive effectiveness.

Cloud computing providers supply their customers with different levels and quality of service through the Internet, according to a pay-as-you-use basis [5]. NIST (National Institute of Standards and Technology) has created the most accurate definition of cloud computing which stated that the cloud model advances accessibility and comprises the most critical characteristics that are delivered such as accessibility, availability, reliability, elasticity, manageability, and high performance [6].

Cloud computing architecture consists of three services layers: Software as a Service (SaaS); Platform as a Service (PaaS) and Infrastructure as a Service (IaaS) including applications, platforms, infrastructure, and servers. Cloud computing is available in one of four deployment models which comprise $[7,8]$.

- Private cloud: the infrastructure is dedicated to the use by a particular organization that contains multiple users to hold and manage it.

- Community cloud: in this model the infrastructure is shared between some organizations from a specific community with common interests (e.g., security needs) whether managed internally or externally. 
- Public cloud: the cloud infrastructure is conveyed free for all populations where cloud service providers possessed, controlled and driven it.

- Hybrid cloud: This model consists of at least two cloud infrastructures to deliver services (resource, servers, storage, databases, processing, etc.) for customers according to the form of Service Level Agreements (SLA) that describes the quality of services.

Cloud computing security: Security is very essential when developing cloud services and applications. The customer concerns appear regarding cloud security, because the customer data, information, and programs are stored in the cloud provider's servers $[9,10]$. The main objectives of cloud computing security include (1) availability: services must be accessible whenever and wherever the customer needs; (2) authentication: the confirmation of the identity of individuals is associated with web communication; (3) accountability: the cloud computing systems ensure the agreement of individuals' involvement in data transmission among the systems; (4) confidentiality: the user's data should be protected in the cloud systems by permitting its accessibility only to authorized people; (5) integrity: the cloud systems confirm that the data has not been modified when it is stored, processed and transmitted; (6) portability: the ability to move services, applications, and data from one cloud computing environment to another with minimal cost.

\section{RELATED WORK}

Rajan et al. (2018) in [1] proposed a system that only focused on specializations taken by engineers through reliable and flexible online exams. The online test starts with specialization questions related to the field and continues to the end based on the user's inputs. The system provides the user with a report of their performance and a suggested career path in which the user is more likely to succeed.

V. Kantha., et al. (2018) in [11] explained that psychological factors of a student help in selecting the appropriate career. The authors presented the design of an expert system used to assess the psychological factors of a student, build a cognitive model and identify the most suitable career. In order to evaluate these psychological factors and provide career guidance to a student, the system asks the student to play the concentration game many times, and based on the student scores, the system builds a cognitive model for the student and suggests a suitable career to him/her.

Musa Peker et al. (2017) in [12] proposed a fuzzy-based method to traditional career guidance practices. The authors introduced a web-based career guidance system called "WEB-CGS". The system focuses only on school students' interests with regard to the fields of information technology, electrics-electronics, accounting, and automotive. The researchers used a set of inputs including the GPAs of mathematics-based and social studies-based classes and career interest values. This research was conducted by questionnaires and teacher-view values input set obtained through interviewing classroom guidance teachers. The system output was determined with respect to the four selected professional fields; therefore, a more comprehensive study could be applied in the future to all other professional fields.
Tajul R., et al. (2014) in [13] proposed a career recommendation system using a fuzzy logic technique. The study has explained that the use of fuzzy logic helps students by giving career recommendations based on career tests.

Wong and Yuen (2019) in [14] presented an overview of the evolution of career guidance in secondary schools in Hong Kong over the last 60 years. The first development (1950-1970) the earliest models of career guidance began in this period after World War II and the Cultural Revolution in China. The second development (1970-1990) represents the gradual evolution from a vocation-oriented approach to a developmental approach in career guidance. The third development (1990-2000) resented the importance of career guidance in school programs with great involvement of all teachers. The development (2000-2018) has seen continual growth in career guidance practices within schools based on recent theories of career guidance.

Hooley (2019) in [15] has presented a report on the issue of quality assurance in career guidance. The report is based on 6 case studies in different countries that assure their career guidance provision. The objective of this research is to use these international examples to inform the development of a quality system for career guidance in Norway. The report focuses on six domains of quality assurance including (1) career guidance policies, investigating to monitor and evaluate their effectiveness; (2) defining what kinds of organizations should be allowed to deliver career guidance and how it should work; (3) considering what processes should be followed to deliver good career guidance; (4) specifying the qualifications and skills of people that can practice career guidance; (5) explaining the results that could be produced through the career guidance process; (6) recognizing the experience of career guidance users and developing tools to gather their perspective.

\section{THE PROPOSED FUZZY LOGIC MODEL}

In this paper, the researcher used the Fuzzy Logic (FL) model, introduced by Zadeh (1995) to represent and process the inputs [16]. Fuzzy logic depends on the mathematical theory of fuzzy sets that is a generalization of the traditional set theory. In FL, we used a new notation of "degree" for verifying a condition. In addition to the state of True/False of a condition, the FL approach enables a condition to be in other states. Fuzzy logic provides good elasticity for logical reasoning, and it takes into account the inaccuracies and uncertainties states. FL model was introduced as a rule-based tool that uses fuzzy theory for handling vagueness. The used Fuzzy Logic model is composited of four basic stages include:

1. Fuzzification: is the process of changing real scalar values into fuzzy values (linguistic variables). This is performed by membership functions. 
2. Inference Engine: is the process of performing the inference operations on the rules, and generates a fuzzy subset as a fuzzy output variable for each rule.

3. Knowledgebase: it includes a rule base and a database, which is gathered from all fuzzy subsets assigned to each output variable.

4. De-Fuzzification: is the process of transforming a fuzzy output set to useful and understandable output values (crisp output) [17].

The main goal of this research is to measure the effectiveness of using career and educational guidance systems through cloud service, using the Fuzzy Logic technique. The new technique will help the organization to combine a group of skills as inputs and turn out the correct choice call as output. The proposed fuzzy logic-based model that used by the researcher for representing the input processing of the career and educational guidance system is described below [18]:

We've represented the set of $n$ input careers $c_{i}$ by a set $C=$ $\left\{c_{i}: c_{i}\right.$ is career $\left.i, 1 \leq i \leq n\right\}$, and represented the set of $m$ features $f_{j}$ related to these careers by $\boldsymbol{F}=\left\{f_{j}: f_{j}\right.$ is a feature related to a career in $\boldsymbol{C}, 1 \leq j \leq m\}$. The researcher denoted the set of fuzzy values related to each feature in the model by $F V=\left\{f v_{j}: v_{j}\right.$ is a fuzzy value, $\left.1 \leq j \leq m\right\}$, where the fuzzy value $f v_{j}$ is chooses from a set $\{$ weak, good, very good, excellent . Therefore to determine the user skills and experiences, we have to search for all features in set $\boldsymbol{F}$ and assign a fuzzy value $f v_{j}$ to each feature. Hence the researcher defined the set of user's skills and experiences $\boldsymbol{S}$, for all $m$ features having an appropriate fuzzy value $f v_{j}$ as:

$$
\boldsymbol{S}_{m}=\left\{\left\langle f_{j}, v_{j}\right\rangle: f_{j} \in \boldsymbol{F}, v_{j} \in \boldsymbol{V}, 1 \leq j \leq m\right\} .
$$

For example, user's skills and experiences can be identified as $<$ Programming, excellent $>$.

We have considered the three fuzzy logic values: Yes, Maybe, and No, for representing a certainty of career presence for a given user.

Therefore, for a given career $c_{i} \in \boldsymbol{C}$ there exists a set $f_{j} \in \boldsymbol{F}$ of $m$ relevant features; $1 \leq j \leq m$. Each feature will take a grade of fuzzy value $f v_{j} \in$ \{weak, good, very good, excellent $\}$. So, we can represent the career records as a set of triples $<c_{i}, f_{j}$, $f v_{j}>$.

This means that, for every career $c_{i}$, the system will generate the set of related features to that career and store the appropriate fuzzy value, $f v_{j}$ for every entry in the career table based on knowledge base rule and experience. The skills and experiences data set $\boldsymbol{S}_{m}$ is created and stored in the skills and experiences table, through the implementation of the user query for selecting an appropriate career. In addition to other attributes, the skills and experiences table contains the two main attributes (a feature of career, and related fuzzy value), i.e., $\left\langle f_{j}, f v_{j}>\right.$.

The effectiveness of the feature $f_{j}$ on the right career decision can be directly obtained from the career table $\mathrm{Ct}$ $\left\{<c_{i}, f_{j}, f v_{j}>\right\}$. The fuzzy value $f v_{j}$ is obtained from the skills and experiences tables for a given feature $f_{j}$ as $\boldsymbol{S}\left(f_{j}\right)$. The author denoted the effect of the feature $f_{j}$ by $E_{i j}$, where $E_{i j} \rightarrow C t$ $\left\{<f_{j}, \boldsymbol{S}\left(f_{j}\right)>\right\}$ which equal one of the fuzzy set values $\{$ Yes, Maybe, No . Depending on the above definitions, we have computed all $m$ relevant features for all career, to get the final career decision, for the $i^{\text {th }}$ career $E_{i}$, where;

$$
E_{i}=\sum_{j=1}^{m}<f_{j}, s\left(f_{j}\right)>
$$

To produce the final output, we should translate the previous fuzzy output set to crisp values that specify the certainty of presence for every career in the set $\boldsymbol{C}$, this process is called the De-fuzzification process.

We've supposed the selected career $c_{i}$ has set of $m$ related features $f_{j}$, then the final selection decision of this career is given by equation (1). We've represented the result of the certainty of career presence using the fuzzy set $\{$ Yes, Maybe, No , as $a^{*}$ Yes, $b^{*}$ Maybe, and $c^{*}$ No; where $a+b+c=m$ and $a \geq b \geq c$. Therefore the total selection decision is computed by;

$$
E_{i}=a^{*} \text { Yes }+b^{*} \text { Maybe }+c^{*} \text { No }
$$

Finally, the crisp percentage value for the selection decision of a given career $c_{i}$ is computed by:

$$
\mathbf{C r}=\left(\mathbf{C} \mathbf{r}_{i} / \mathbf{C} \mathbf{r}_{j}\right) / 100 \%
$$

Where, $\mathbf{C} \mathbf{r}_{i}$ is the centroid of overall selection decision fuzzy set value, and $\mathbf{C} \mathbf{r}_{j}$ is the centroid for the Yes fuzzy set.

\section{IMPLEMENTATION OF CAREER AND EDUCATIONAL GUIDANCE SYSTEM}

The GUI of the proposed career and educational guidance system is entirely cloud-based. The system will be divided into four apps called school level, university level, graduated, and system admin. The proposed system architecture consists of three components: client, server, and database management system.

The system requirements are documented in an integrated set of diagrams (e.g., DFD, use case, class, sequence, etc.). Each diagram provides a different perspective of the system design. The integrated combination of these models forms the services that should be performed by the system. The system requirements are classified into functional and non-functional requirements [19].

The four main users of the system include administrators, school-student, university-student, and graduates. Each user interacts with their services according to given privileges. The system provides the following apps (services) to each user:

School-level app: school students use this app to search for an interested major in KSA universities. The system provides the student and parent with the requirements of the selected department for a specific college in the university (or university branch).

University-level app: university students use this app to search for training courses (offered by specific training center) to develop their skills. On the other hand, students use this app to know the job requirements offered by public and private organizations for preparing themselves for working in the future. Graduate app: graduated student uses this app to inquire about available jobs in the public and private sectors, and hence apply for a job position. The app displays a list of all available jobs (sorted by advertising date) in each company stored in the DB system. Also, the graduate student can use this app to search for training courses needed for a specific career. 
System admin app: This app provides the system admin with a simple GUI tool to manage easily the basic information of the proposed system. Initially, the system admin app includes the following services: add new records, update existence records, delete unwanted records, and print useful information from the system database using the app forms.

The educational and career guidance system is implemented as mentioned above. It consists of four main subsystems namely: Admin app, School level app, University level app, and Graduated app. The first process for the user before using the desired service or app is to register to the required app by providing the following data (username, password, confirmed password, email, phone no., and user type).

If the user is acting as admin, then he/she can manage (i.e., add, update, and delete) all the basic system information such as: universities, branches, colleges, departments, department requirements, users, companies, careers, career requirements, training center, and training courses. While, if the user acts as a school student, then he/she can use the system to search for a specialization in a specific university, and to search for the requirements of the desired department in a selected college in a specific university. If the user acts as a university student, then he/she can use the system to search for training courses (offered by a specific training center). On the other hand, students use this app to know the job requirements offered by public and private organizations that help them for working in the future. Finally, if the user acts as a Graduate student, then he/she can use the system to search for currently available jobs in the public and private sectors, and hence apply for a job position. The app provides a list of all available jobs in each company sorted by the advertising date as well as the graduate student can use this app to search for training courses needed for a specific career.

\section{RESEARCH HYPOTHESIS, ANALYSIS, AND OUTCOMES}

The objective of this research is to present the effectiveness of using the cloud-based educational and career guidance system for the graduates and students. To develop this goal, we have implemented a web-based survey. The survey was distributed among many students and graduates based on various categories including: gender, age, class standing, enrollment status, specialization, and city. We have completed the study by analyzing and evaluating the performance of the proposed survey. The research point hypothesis states that, "There is a positive impact of different dimensions of dominating practices in using cloud-based educational and career guidance system for the graduates and students". The research key hypothesis variables are divided into dependent and independent variables:

Dependent variables: the variables of enriching career development and improving learning quality, through the use of cloud-based career and educational guidance apps as interactive and effective tools.

Independent variables: the dimension of dominating practices of using the cloud-based career and educational guidance system for the graduates and students, as shown in points $(1: 10)$ in the questionnaire.

In this study, the Stepwise Multiple Linear Regression model is used to determine and prove the positive impact of the different practices of using the career and educational guidance system as a cloud service. This model was used to identify the variables affecting the performance and quality of using system services through the cloud environment. Spearman Correlation analysis was also used to identify the relationships between dependent and independent variables. In this analytical way, the hypothesis validity was determined and tested.

The descriptive statistics data related to the research samples were extracted and analyzed by the research team. On the other hand, the descriptive statistics of the dependent and independent variables were also analyzed, using arithmetic means, standard deviation, and coefficient of standard variation. The distribution percentages of the selected Likert Scale items used in the study refers to the following experimental results:

- $65 \%$ of the students and graduates answers tend to "strongly agree",

- $22 \%$ of the students and graduates answers tend to "very satisfied",

- $15 \%$ of the students and graduates answers tend to "agree", and

- $05 \%$ of the students and graduates answers tend to "neutral",

- $03 \%$ of the students and graduates answers tend to "disagree".

Cronbach's alpha tests were used for measuring the validity and reliability of the study questionnaires' content as well as the consistency of the dependent and independent variables.

These tests were used also to measure effects on enriching performance and quality of using the system as a cloud-based career and educational guidance service. These results reflect the high validity of the study sample which reflected also to the face validity of the content of the proposed app that reached (0.85690).

\section{A. Demographic Variables Analysis}

We have presented the descriptive statistics of the demographic variables include gender, age, class-level, enrollment status, specialization, and city. Figure 1, shows that the distribution of the research sample according to gender refers that males sample got $72.4 \%$ against $27.6 \%$ for females.

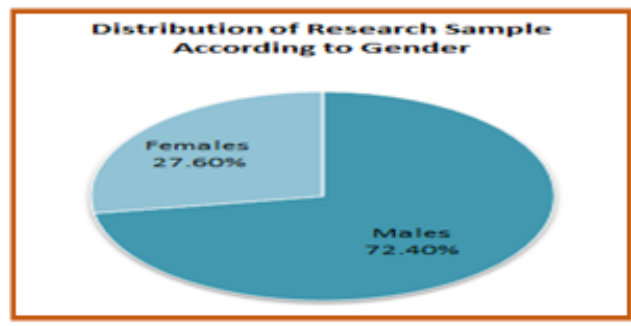

Fig. 1. Distribution of the research sample according to gender 
Figure 2, shows that the distribution of the research sample according to class level of students refers that: (53.1\%) followed by students of fifth level, (32.4\%) followed by fourth-level students, (8.3\%) followed by third-level students, (3.4\%) followed by second-level students, and finally (2.8\%) followed by first-level students of the research samples.

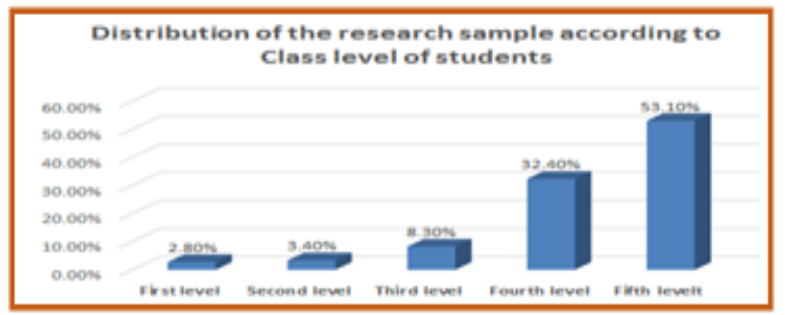

Fig. 2. Distribution of the research sample according to the class level

The most important questions in school-level students' questionnaire were categorized and ordered as follows:

1. Does the system provide you all the information you need for your future college?

2. Do you benefit from the system website to know your scientific orientation?

3. Does the system provide all the requirements for your selected specialization?

4. Do you need help in using the system to choose a university, college or department?

5. Does your parent help you to choose the right specialization?

6. What is your assessment of the services provided by the system?

7. Did you find all that you're looking for while using the system?

8. Could you depend on the system to get the information you need in about your future career?

9. Do you need other services that are not provided on the current version of the system?

10.If you choose the appropriate major, do you need more information from the system?

Some important questions in university-level students' questionnaire include:

1. Does the system provide you with enough information about your college?

2. Does the system provide you with enough information about the courses offered for specific majors?

3. Does the system services help you to choose the right career in the future?

4. Does the system develop your decision-making abilities to choose the right career?

5. Does the system develop your decision-making abilities to choose the right training courses?

Finally, some important questions in the graduates' questionnaire include:

1. Does the system provide you with most careers (job opportunities) provided by public or private companies?

2. Does the system provide you with most training centers required for a specific career?

3. Does the system help graduates to improve their skills and abilities to select the right career?
4. Could the system help graduates to improve their skills and abilities to select the right training courses?

5. Does the system provide graduates with careers offered by companies?

6. Is the information on the system website recent and useful for graduates?

Table (1) shows a positive direction of the research sample results and a general trend towards the agreement on using career and educational guidance cloud-based system for careers' consulting and searching training courses for students and graduates, in arithmetic mean (2.372) and coefficient of standard variation (55.124).

Spearman Correlation Matrix is presented to specify the relationship between the dimensions of dominating practices of using career and educational guidance system as a cloud service. The study has concluded the following result

The research result has shown that there is a positive relationship between the dependent and independent variables related to dimensions of practices in using career and educational guidance system as a cloud service, at a significance level less than (0.01), (0.05) which proves the validity of the research key hypothesis.

Spearman correlation was used to identify the relationship strength and direction between the variables of using career and educational guidance system as a cloud service, and its effect on the learning outcome and quality. 
Table- I. The descriptive analysis of using career and educational guidance system for the graduates and students

\begin{tabular}{|c|c|c|c|c|}
\hline $\begin{array}{c}\text { Items } \\
\text { (questions) }\end{array}$ & $\begin{array}{c}\text { Weighted } \\
\text { Arithmetic } \\
\text { Mean }\end{array}$ & $\begin{array}{c}\text { Standard } \\
\text { Deviation }\end{array}$ & $\begin{array}{c}\text { Coefficient } \\
\text { of Standard } \\
\text { Variation }\end{array}$ & Order \\
\hline Q\#1 & 1.84 & 1.041 & 56.71 & 2 \\
\hline Q\#2 & 1.88 & 0.879 & 49.75 & 3 \\
\hline Q\#3 & 1.97 & 1.281 & 54.81 & 5 \\
\hline Q\#4 & 1.72 & 0.972 & 51.89 & 1 \\
\hline Q\#5 & 3.02 & 1.201 & 57.70 & 8 \\
\hline Q\#6 & 2.10 & 1.268 & 56.91 & 6 \\
\hline Q\#7 & 3.10 & 1.141 & 59.25 & 9 \\
\hline Q\#8 & 3.31 & 1.341 & 56.77 & 10 \\
\hline Q\#9 & 1.96 & 1.179 & 56.80 & 4 \\
\hline Q\#10 & 2.82 & 1.103 & 50.65 & 7 \\
\hline
\end{tabular}

We've determined the most independent variables affecting the quality of the implementation of the system by applying Stepwise Multiple Linear Regression analysis. In this context, we have used T-Test for measuring the effect of each independent variable separately in the regression model in the presence of a significance level less than (0.05). If the significance level is $<(0.05)$, this indicates the positive effect of such independent variable, and conversely, if the significance level is $>(0.05)$, this means that there is no effect, hence then stop and exit from the regression model. By that same way, we have tested all independent variables by using F-Test to measure the effect of all variables in the regression model. If the effect level is $<(0.05)$, this means that there is a good and positive effect of such independent variables and vice versa.

To measure the independent variables affecting the enrichment of using career and educational guidance system for careers' consulting messages via cloud service, the following equation was used:

$Y=B_{0}+B_{1} Q_{1}+B_{2} Q_{2}+\ldots+B_{9} Q_{9}$

Where, $Y$ is the expected value of the dependent variable and represents the enrichment of using career and educational guidance system as a cloud service, $\mathrm{Q}_{1}$ through $\mathrm{Q}_{9}$ are distinct independent or predictor variables, $B_{0}$ is the value of $Y$ when all of the independent variables are equal to zero, and $B_{1}$ through $B_{9}$, are the estimated regression coefficients. Each regression coefficient represents the change in $Y$ relative to a one-unit change in the respective independent variable. By substituting the values of independent variables according to the Likert Scale, the expected value of enrichment of using career and educational guidance system can be reached.

$Y=3.642-0.018 Q_{1}-0.031 Q_{2}+0.014 Q_{3}+0.062 Q_{4}-0.037 Q_{5}+$ $0.03 Q_{6}-0.028 Q_{7}-0.018 Q_{8}+0,011 Q_{9}$

\section{RESULT AND DISCUSSION}

The following figures and discussion show the results of a Web-based evaluation implemented by 400 students sample at KKU during the second semester of the 2018/2019 academic year.

Figure 3, presents a histogram that shows the actual and predicted variables values for using career and educational guidance system as a cloud service.

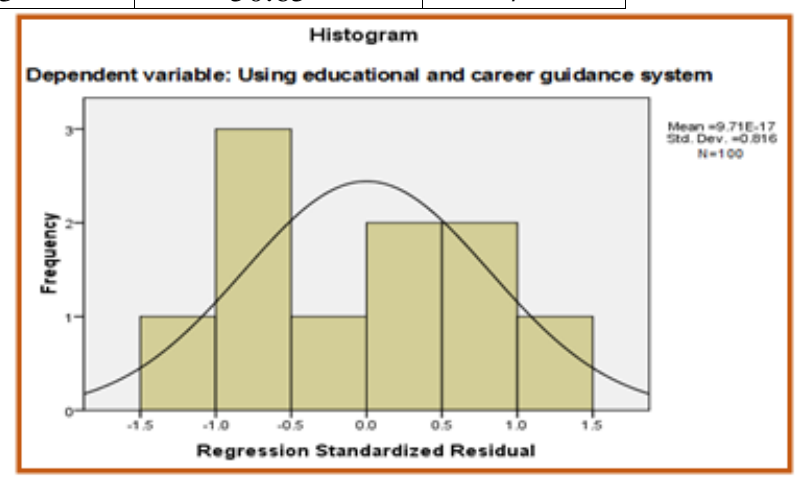

Fig. 3. Histogram for individuals that have used career and educational

Figure 4, indicates that $53 \%$ of students are from the Computer Science Department, 26\% of students are students from the English Language Department, and 21\% of students are from the Mathematics Department have participated.

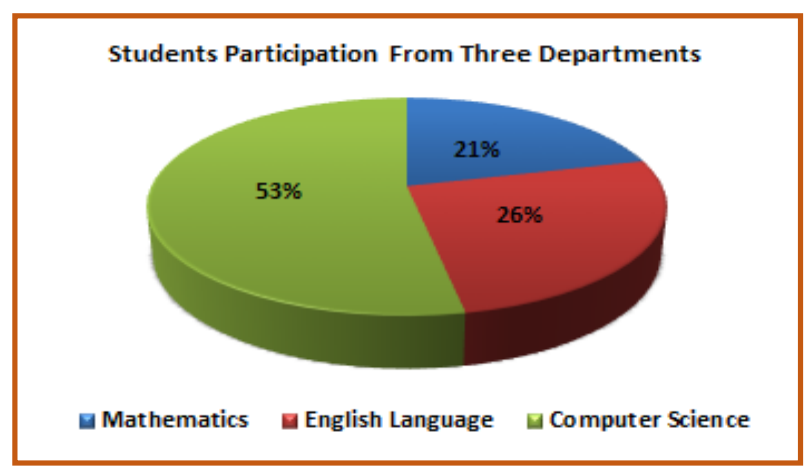

Fig. 4. Students Participation

Figure 5 shows the feedback of the school-level students on the question if the system provides students all the information needed for their future college (question 1 in school-level students' questionnaire). For each department, the number of students is shown through the vertical axis and the ranking through the horizontal axis. 


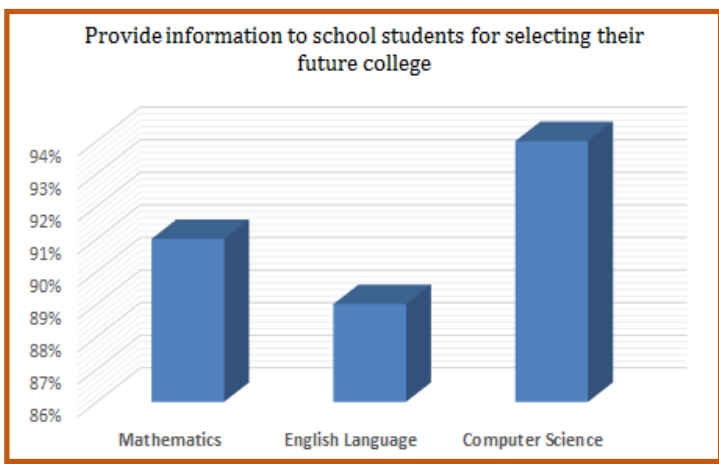

Fig. 5. Provide information to school student to select future college

Figure 6 shows the feedback of the university-level students on the question if the system develops your decision-making abilities to choose the right career (question 4 in university-level' questionnaire).

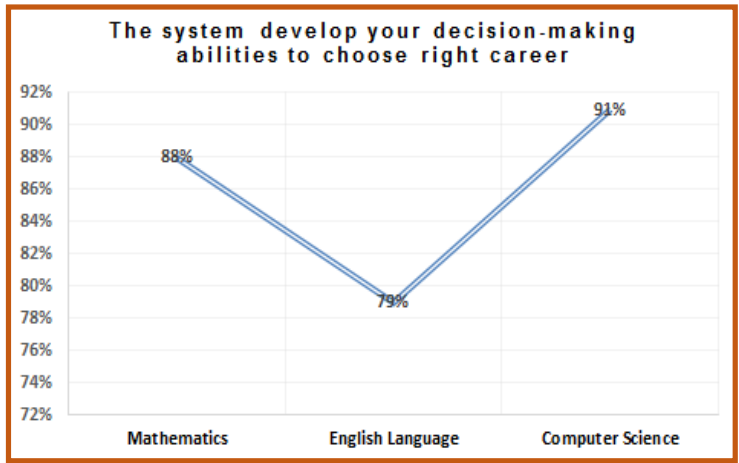

Fig. 6.The system develop your decision-making abilities to choose the right career

Figure 7 shows the response of the graduates on the question if the system help graduates to improve their skills and abilities to select the right career (question 3 in graduates' questionnaire).

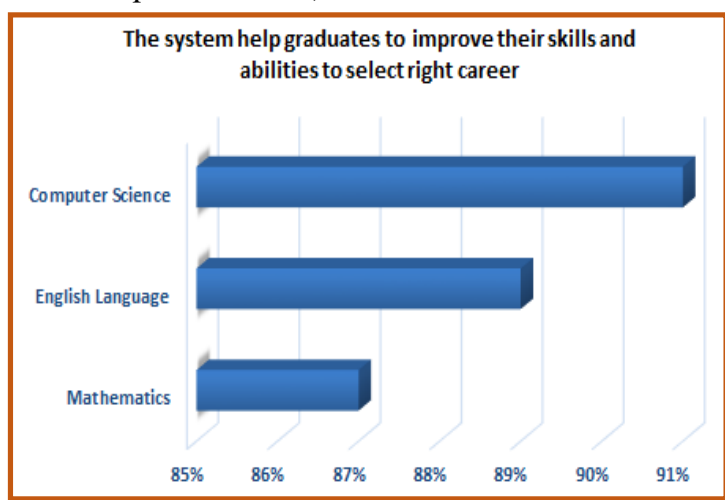

Fig. 7. The system help graduates to improve their skills and abilities to select the right career

Most educational organizations especially, in the Middle East region are seeking for moving to the digital transformation age by improving current systems and

implement integrated systems using cloud computing architecture. The educational organization can improve itself by applying or using recent technologies to facilitate and implement novel educational apps to help students in academic and social life, and hence receiving and acting on feedback from users. Furthermore, students, motivation is increased when realizing that the university is helping them by providing tools and apps that facilitate their success as learners as well as graduates.
Weve implemented web-based questionnaires to collect students, and graduates' feedback about the effectiveness of using the cloud-based career and educational guidance system. It shows that:

- The majority of students think that the system has developed their decision-making abilities to choose the right career.

- The majority of school students think that the system helps them in improving their skills and abilities to select the right career.

- The majority of students think that the system is so effective means of interactions between students and the labor sector.

- Students' preferences are different based on major. For example, the English department students have less assessment for the question: does the system develop your decision-making abilities to choose the right career?", and the Mathematics department students have a very good evaluation, while computer science students have higher positive feedback about the same question.

The evaluation showed that the proposed system has strongly contributed to the effectiveness of using the career and educational guidance system as a cloud service by improving the quality of students' comprehension.

\section{CONCLUSIONS}

The objective of this research is to present the effectiveness of using career and educational guidance system as a cloud service for graduates and students. We have implemented three web-based questionnaires for (school-level students, university-level students, and graduates). The survey was conducted on many graduates and students and based on different factors such as gender, age, class standing, enrollment status, specialization, and city. The proposed system is introduced as a "Career-s-a-Service" cloud system. The system inputs are processed using Fuzzy Logic operations. Cronbach's alpha tests are used for measuring the validity and reliability of the study questionnaires' content. Several analysis methods such as Spearman correlation, stepwise multiple linear regression, skewness, mean, and standard deviation have been used in this study to determine the effect on the performance of the dominating categories such as gender, age, class standing, enrollment status, specialization, and city on the variables of using the system as a cloud-based career and educational guidance service. The research study concluded that there is a positive relationship between the dependent and independent variables related to dimensions of practices in using career and educational guidance system as a cloud service, at a significance level less than (0.01), (0.05) which proves the validity of the research hypothesis.

\section{ACKNOWLEDGMENT}

The author extends his appreciation to the Deanship of Scientific Research at King Khalid University for funding this work through General Research Project under grant number (GRP-35-40 /2019).

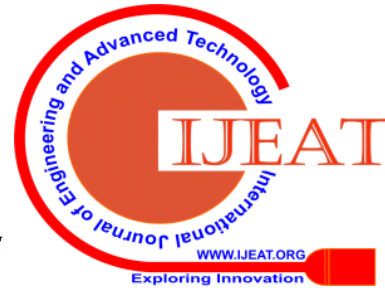




\section{REFERENCES}

1. Rajan S., Ronit P., Kaushik K., Gursimran S., "Career Guidance System". International Journal of Advanced Research in Computer and Communication Engineering. ISO 3297:2007 Vol. 7, Issue 2, DOI 10.17148/IJARCCE.2018.7230, February 2018.

2. https://en.wikipedia.org/wiki/Career - 22, October 2018.

3. CICA, "Professional Standards for Australian Career Development Practitioners". Career Industry Council of Australia Incorporated - ISBN 064277604 0, www.cica.org.au, 2006 Revised 2007, 2011.

4. Raj Kishor Bisht, "A fuzzy based Conceptual Framework for Career Counselling”. Department of Applied Sciences - Amrapali Institute of Technology and Sciences, Haldwani, Uttarakhand, India.

5. Hosam F. El-Sofany, Abdulelah Al Tayeb, Khalid Alghatani, and Samir A. El-Seoud, "The Impact of Cloud Computing Technologies in E-learning", International Journal of Emerging Technologies in Learning - iJET, Volume 8, Special Issue 1: ICL2012, Pages 37-43, http://dx.doi.org/:10.3991/ijet.v8iS1.2344, January 2013.

6. Final Version of NIST Cloud Computing Definition Published. Available online: http://www.nist.gov/itl/csd/ cloud-102511.cfm (accessed on 14 December $t$ 2017).

7. Jain, P.; Rane, D.; Patidar, S. "A survey and analysis of cloud model-based security for computing secure cloud bursting and aggregation in renal environment”. In Proceedings of the 2011 World Congress on Information and Communication Technologies (WICT), Mumbai, India, 11-14 December 2011; pp. 456-461.

8. Gowrigolla, B.; Sivaji, S.; Masillamani, M.R. "Design and auditing of cloud computing security". In Proceedings of the 2010 5th International Conference on Information and Automation for Sustainability (ICIAFs), Colombo, Sri Lanka, 17-19 December 2010; pp. 292-297.

9. McKendrick J., (2011), "Loud Divide: Senior Executives Want Cloud, Security and IT Managers are Nervous", 15-12-2017, http://www.zdnet.com/ blog/ serviceoriented/ cloud-divide-senior-executives-want-cloud-security-and-it-managers-ar e-nervous/6484

10. Hosam F. El-Sofany, "Proposed a Novel Mechanism to Detect and Prevent XML and HTTP-based Denial-of-Service Attacks for Cloud Computing". The 2018 International Conference on Network Technology (ICNT 2018), and 7th International Conference on Software and Information Engineering (ICSIE 2018). Cairo, Egypt on May 4-6, 2018.

11. V. Kantha, V. Chandra, A. Jyothsana, T. Sainadh, P. Harshitha. "Assessing Psychological Factors of a Student Through Concentration Game for Career Selection". International Journal of Engineering \& Technology. 7 (2.32) 443-445, 2018.

12. Musa Peker, Hüseyin Gürüler, Baha Şen, Ayhan İstanbullu. "A new fuzzy logic based career guidance system: WEB-CGS", Tehnički vjesnik 24, 6(2017), ISSN 1330-3651 (Print), ISSN 1848-6339 (Online), https://doi.org/10.17559/TV-20151105201325, 2017.

13. Tajul R., Muhamad A., Noor M., Iman H., Nur F. "Career Path Recommendation System for UiTM Perlis Students Using Fuzzy Logic". IEEE Conference:, DOI: 10.1109/ICIAS.2014.6869553, June 2014.

14. L.Wong, M. Yuen "Career Guidance and Counseling in Secondary Schools in Hong Kong: A Historical Overview". Journal of Asia Pacific Counseling, Doi : 10.18401.2019.9.1.2., Vol.9, No.1, 1-19, 2019.

15. Hooley, T. "International approaches to quality in career guidance". Oslo: Skills Norway, Report prepared for Skills Norway, April 2019.

16. Zadeh LA. Fuzzy sets. Inf Control 8:338-53, 1965.

17. Dweiri FT, Kablan MM. "Using fuzzy decision making for the evaluation of the project management internal efficiency". Decision Support System Journal;42:712-26, 2006.

18. Hosam F. El-Sofany, Samir A. El-Seoud. “A Cloud-based Educational and Career Guidance Model using Fuzzy Logic Concepts". The 2nd. International Conference on Network Technology (ICNT 2019), and 8th International Conference on Software and Information Engineering (ICSIE 2019). Cairo, Egypt on 4-6 May 2019.

19. Hosam F. El-Sofany, Samir A. El-Seoud. "Educational and Career Guidance Cloud-based System to Improve Learning Outcomes". 22nd International Conference on Interactive Collaborative Learning (ICL2019), 48th IGIP International Conference on Engineering.

\section{AUTHORS PROFILE}

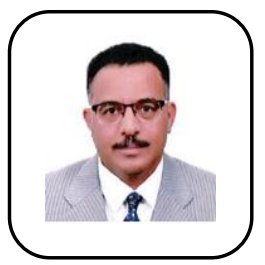

Hosam F. El-Sofany received his Ph.D. and M.Sc. degrees in Computer Science. He is currently an Associate Professor of CS at King Khalid University, KSA (and Cairo Higher Institute for Engineering, Computer Science and Management- Egypt). His research interest includes Cloud computing, E-learning, M-learning, U-learning, Fuzzy logic, Cloud security, Cybersecurity, and Semantic Web. He has published about 70 research papers in international refereed journals and international conferences. He is acting as a reviewer for many international journals and conferences. He has also supervised many M.Sc. and Ph.D. dissertations of Computer Science and Information Systems. Hosam has acted as a chairman of the Graduate Studies and Scientific Research Committee at KKU University. 